\title{
Análise da evolução do arcabouço legislativo no trato dos recursos hídricos no Brasil até a Lei 9.433/97
}

A crise em torno da possibilidade de finitude dos Recursos Hídricos, tem levado a sociedade a buscar caminhos como forma de enfrentamento dessa problemática. No Brasil, ao longo de décadas inúmeras ações foram implementadas, no sentido de combater e amenizar a crise da água, bem como instrumentos legais de regulação de uso. Assim, o objetivo do trabalho consiste em analisar a evolução das políticas públicas de água no Brasil. A metodologia utilizada foi uma revisão bibliográfica entre maio de junho de 2018, a partir da consulta em livros, periódicos, revistas científicas e legislação sobre águas. Concluiu-se que, apesar de inúmeros mecanismos legais voltados à proteção das águas, a maioria estava voltada apenas para interesses políticos e econômicos. Só a partir da Lei $9.433 / 97$ é que os Recursos Hídricos no Brasil passaram a gozar de proteção e regulação, quanto ao uso e qualidade.

Palavras-chave: Recursos Hídricos; Políticas Públicas de água; Lei 9.433/97.

\section{Analysis of the evolution of the legislative framework in the treatment of water resources in Brazil until Law 9.433/97}

The crisis around the possibility of finitude of water resources has led society to look for ways to deal with this problem. In Brazil, over the course of decades, numerous actions have been implemented to combat and alleviate the water crisis, as well as legal instruments to regulate its use. Thus, the objective of this pape is to analyze the evolution of public water policies in Brazil. The methodology used was a literature review between May and June 2018, based on consultation in books, journals, scientific journals and water legislation. It was concluded that, despite numerous legal mechanisms for water protection, most were directed solely to political and economic interests. Only from Law 9,433 / 97 did the Water Resources in Brazil enjoy protection and regulation, regarding its use and quality.

Keywords: Rainwater abstraction; Microdrainage; Precipitation.

Topic: Planejamento, Gestão e Políticas Públicas Ambientais Reviewed anonymously in the process of blind peer.
Received: 07/06/2019 Approved: 10/08/2019
Jane Arimércia Siqueira Soares

Universidade Federal de Campina Grande, Brasi

http://lattes.cnpq.br/6142027127506496

jane_arimercia@hotmail.com

Renata Maria Brasileiro Sobral Soares

Universidade Federal de Campina Grande, Brasi

http://lattes.cnpq.br/8315657815493005

renatambsobral@hotmail.com

\section{Erivaldo Moreira Barbosa}

Universidade Federal de Campina Grande, Brasil

http://lattes.cnpq.br/5857151126212299

erifat@terra.com.br
Referencing this:

SOARES, J. A. S.; SOARES, R. M. B. S.; BARBOSA, E. M.. Análise da evolução do arcabouço legislativo no trato dos recursos hídricos no Brasil até a Lei 9.433/97. Nature and Conservation, v.12, n.2, p.50-59, 2019. DOI: http://doi.org/10.6008/CBPC2318-2881.2019.002.0006

DOI: 10.6008/CBPC2318-2881.2019.002.0006 


\section{INTRODUÇÃO}

Durante muito tempo, pensou-se que a água seria um recurso natural inesgotável. Entretanto, com o passar das décadas, notou-se que tal premissa não condizia com a realidade, pois apesar de ser o recurso em maior abundância no planeta Terra, a maior quantidade disponível é imprópria para consumo, pois se trata de águas dos oceanos. Um fator determinante para a crise da água se deu pela sua má utilização e desperdício, mas aspectos climáticos e regionais também fazem parte da má distribuição da água doce no mundo. $\mathrm{O}$ crescimento populacional e a demanda de água somam outro fator de peso determinante para a escassez de água.

No Brasil a principal causa da crise hídrica está na má distribuição das chuvas e na demanda pelo uso, principalmente na agricultura. Nisto surge a necessidade de mecanismos que disciplinem o uso da água. Assim, o objetivo do trabalho, consiste em fazer uma análise da evolução legislativa do arcabouço legal no trato dos recursos hídricos no Brasil até a Política Nacional de Recursos Hídricos, a Lei 9.433/97. A presente pesquisa justifica-se pela contribuição teórica no campo da discussão no trato com os recursos hídricos.

\section{MATERIAIS E MÉTODOS}

A metodologia utilizada foi uma revisão bibliográfica entre maio de junho de 2018 a partir da consulta em livros, periódicos, revistas científicas e legislação sobre águas. A pesquisa utilizou-se de três palavraschave como recursos hídricos, políticas públicas de recursos hídricos e Lei 9.433/877, bem como produções científicas voltados para a área de recursos hídricos no Brasil.

\section{DISCUSSÃO TEÓRICA}

\section{Evolução do Arcabouço legislativo no trato dos Recursos Hídricos no Brasil até a Lei 9.433/97}

O tratamento dado aos recursos hídricos na história brasileira demonstra uma evolução do despertar pela conservação da água por parte dos legisladores e de toda a sociedade. De início o que se vislumbram são atos normativos limitados a atribuições específicas a problemas pontuais; porém, o que se vê ao longo do tempo é uma transformação da importância dada a água enquanto recurso natural limitado.

A Constituição Federal de 1891, ao dispor sobre águas, limitou-se a definir a competência federal e estadual para legislar sobre águas no Direito civil, conforme artigos 13 e 14 da referida carta, onde consta que é direito da União e dos Estados legislarem sobre viação férrea e a navegação interior será reservada por lei federal e privatiza a competência ao congresso nacional de legislar sobre rios que banhem mais de um Estado ou territórios estrangeiros (BRASIL, 1891). Enquanto isso, o Código Civil de 1916 limitou-se a disciplinar o direito de vizinhança dentro do direito de propriedade e neste tratava a água como bem privado, podendo o proprietário utilizá-la como bem lhe prouvesse (ARAUJO et al., 2008).

Por outro lado, a Constituição de 1934 foi além das competências e instituiu as águas como bens de domínio da União, conforme incisos II e III do artigo 20, colocando os lagos e quaisquer correntes em seu domínio ou as que banhem mais de um estado, ou sirvam de limites a outros países ou vá a outros territórios 
estrangeiros e as ilhas fluviais e lacustres nas zonas fronteiriças, também as margens dos rios navegáveis que não sejam de domínio de outro ente conforme inciso II do artigo 21 (BRASIL, 1934).

Mas ao passo que a referida carta se limitava a tratar de temas pontuais como competência e domínio neste mesmo ano é promulgado o principal instrumento legal sobre águas, o Decreto № 24.643 de 10 de julho de 1934 ficou conhecido como o 'Código de Águas' (CASTRO, 2005); este, por sua vez, tinha como objetivo atualizar a legislação sobre águas no Brasil adaptando-o as necessidade e interesses econômicos da época (BURITI et al., 2014).

O Código de Águas de 1934 contribuiu para que o poder público disciplinasse o uso da água e o aproveitamento de energia hidráulica no país. Basicamente a intenção legislativa se detinha ao interesse econômico em torno do desenvolvimento das hidroelétricas, pois a maior parte do código se detém ao aproveitamento desse potencial, em linhas gerais ele dividia as águas em águas públicas de uso comum, as de uso comum e os particulares (BARBOSA et al., 2004).

No que tange a Constituição Federal de 1937, não foi possível observar mudanças quanto ao tratamento dado aos recursos hídricos em relação a de 1934, apenas atribuiu competência privativa a União de legislar sobre bens de domínio federal, águas e energia hidráulica conforme dispõe em seu artigo 143 (CASTRO, 2005; BRASIL, 1937). Outros instrumentos normativos que também contribuíram para o avanço em defesa das águas foram a Lei 5.357 de 1967 que veio estabelecer penalidades as embarcações e terminais marítimos fluviais que lançassem detritos e óleos em águas brasileiras embora revogada pela Lei 9.966 de 2000 que por ocasião disciplina a prevenção e poluição causada por lançamentos de óleos e outras substâncias perigosas, para a época, significou um avanço em termos de preservação dos recursos hídricos (BRASIL, 1967; 2000).

Some-se a isso à Portaria GM-0013 do Ministério do Interior de 1976 veio estabelecer o primeiro sistema de classificação das águas interiores e determinou o enquadramento das águas federias e a Portaria Interministerial dos ministérios do Interior e das Minas e Energia no 90 de 1978 instituiu a criação do comitê especial de estudos integrados de Bacias Hidrográficas (CASTRO, 2005). Em 1986, o CONAMA publica a resolução no 20, que estabelece padrões de qualidade da água nos corpos hídricos, classificando-a em classes de acordo com seus usos preponderantes às águas doces, salobras e salinas, seu objetivo foi reformular a classificação já existente para melhor distribuir os usos (BRASIL, 1986).

Em 05 de março de 1987 é publicado o Decreto no 94.076 instituindo o Programa Nacional de Microbacias Hidrográficas sob a supervisão do ministério da agricultura que tinha o intuito de promover um melhor aproveitamento agropecuário dessas unidades ecológicas com adoção de práticas de manejo com previsões de ações descentralizadas (BRASIL, 1987). Esses regramentos supracitados como se verá mais à frente foram bem recepcionados pela Política Nacional de Recursos Hídricos.

Contudo, o que veio modificar o disciplinamento no trato dos recursos hídricos de maneira profunda foi a promulgação de 1988 da Constituição Federal, que diferente das demais, deu uma atenção especial ao meio ambiente e consequentemente aos recursos hídricos, pois até então o direito de águas era disciplinado pelo Código de 1934, a nova carta modificou profundamente os caminhos para a Política Nacional de 
Recursos Hídricos do país, uma vez que derrogou a lei das águas de 1934, deixando de existir as águas particulares dentre outras particularidades (BARBOSA et al., 2012).

O constituinte de 1988 dedicou um capítulo inteiro para tratar sobre meio ambiente, localizado no Capítulo VI, Título VII, além de dispositivos esparsos no corpo constitucional que dispõe sobre águas, o artigo 225 prevê que é direito de todos gozar de meio ambiente ecologicamente equilibrado, nele estando inserido os recursos hídricos, bem como incumbe ao poder público e a toda coletividade o dever de preservá-lo (ARAÚJO et al., 2008). Ainda sobre a Constituição Federal de 1988, ao disciplinar a atuação e proteção do meio ambiente, a carta magna coloca este como cláusula pétrea, como um direito fundamental, estabelecendo a responsabilidade do poluidor no âmbito civil, penal e administrativo, incluindo nestes pontos a água de forma ampla (BITTENCOURT et al., 2014).

Quanto às competências, o artigo 22, inciso IV dispõe sobre a competência privativa da união em legislar sobre águas, o artigo 23 por sua vez vem dispor sobre a competência comum entre a União, Estados, Distrito Federal e municípios para de acordo com os incisos VI e VII, 'proteger o meio ambiente e combater a poluição em qualquer de suas formas' e 'preservar florestas, fauna e flora'. $\mathrm{O}$ artigo 24 dispõe sobre a competência concorrente entre União, Estados e Distrito Federal nos incisos VI e VIII para legislarem acerca de 'florestas, caça, pesca, fauna, conservação da natureza, defesa do solo e dos recursos naturais, proteção do meio ambiente e controle da poluição' e responsabilidades por danos ao meio ambiente (BRASIL, 1988).

Quanto ao domínio, a carta maior prevê, em seu artigo 20, inciso III, que são bens da União, "os lagos, rios e quaisquer correntes de água em terrenos de seu domínio, ou que banhem mais de um Estado, sirvam de limites com outros países ou se estendam a território estrangeiro ou dele provenham, terrenos marginais e praias fluviais" (BRASIL, 1988). Além disso, o artigo 20, em seu §1을 assegura aos Estados, Distrito Federal e aos municípios o resultado da exploração de recursos hídricos para fins de energia elétrica. No artigo 43, §2 IV estabelece a "prioridade no aproveitamento econômico e social dos rios e das massas de água represadas ou represáveis nas regiões de baixa renda sujeitas a secas periódicas" (BRASIL, 1988).

Além desses dispositivos já mencionados no corpo constitucional existem outros tantos que tratam de recursos hídricos, seja de cunho ambiental ou econômico, mas que estão ali inseridos, entretanto dentre esses tantos, o artigo 21, inciso XIX, coloca como competência da União a "instituição de um sistema nacional de gerenciamento de recursos hídricos e definir critérios de outorga e direitos de uso" (BRASIL, 1988), que vem a ser regulamentado a partir da criação da Política Nacional de Recursos Hídricos, instituída pela Lei $9.433 / 97$

Assim, a Constituição Federal de 1988 é considerada um marco legal na história legislativa brasileira, quanto ao trato com o meio ambiente, pois enquanto as demais se limitavam a questões pontuais, essa considerou o meio ambiente como uma garantia fundamental, reservando ao Estado e a coletividade o dever de preservá-lo (ARAÚJO et al., 2008). Assim, feito o caminho legislativo dado à água, perceberam-se que todos os regramentos contribuíram para os avanços no cuidado com os recursos hídricos até a Constituição Federal de 1988, culminando na Política Nacional de Recursos Hídricos instituída pela Lei 9.433/97. 


\section{Política Nacional de Recursos Hídricos Lei 9.433/97}

Antes de iniciarmos a discussão em torno da Política Nacional de Recursos Hídricos, é pertinente apresentarmos alguns conceitos do que vem a ser Políticas Públicas de fato. Políticas Públicas são "ações, práticas, diretrizes políticas fundadas em leis e empreendidas como funções de Estado por um Governo para resolver questões gerais e específicas da sociedade" (HEIDMANN, 2006). Já para Souza (2006) "a formulação de políticas públicas constitui-se no estágio em que os governos democráticos traduzem seus propósitos e plataformas eleitorais em programas e ações que produzirão resultados ou mudanças no mundo real". Assim, neste contexto, pode-se afirmar que a Lei 9.433/97 representa uma política pública fundamentada em lei que tem a função de resolver questões pertinentes aos recursos hídricos.

A Lei 9.433/97, sancionada em 08 de janeiro de 1997, instituiu a Política Nacional de Recursos Hídricos e regulamentou o inciso XIX do artigo 21 da Constituição Federal, pela instituição de um sistema de gerenciamento de recursos hídricos, representando um novo marco institucional no país, incorporando normas, princípios e padrões de gestão já incorporados em outros países (BOSOI et al., 1997). A nova lei das águas trouxe uma proposta de instrumento moderno e democrático, com o objetivo de fornecer subsídios no campo político e de gestão das águas no Brasil (BURITI et al., 2014), corroborando com isso, Santin et al. (2013) completa que "a promulgação dessa lei consolidou um avanço na valoração e na valorização da água" e que por ser inspirada no modelo francês, "a legislação brasileira sobre recursos hídricos tornou-se em um modelo ambicioso de gestão".

A política Nacional de Recursos Hídricos, sobre a qual teceremos comentários a partir daqui, está estruturada em 57 artigos, dos quais se destacam elementos importantes que a compõem. 0 artigo 10 já inicia apresentando os fundamentos no qual se baseia tal regramento incisos I a VII, colocando a água como um bem de domínio público, dotado de valor econômico, finito e vulnerável, a necessidade dos usos múltiplos da água, porém, em casos de escassez devem priorizar-se o consumo humano e a dessedentação de animais, a adoção da bacia hidrográfica como unidade de planejamento e a participação de todos os seguimentos sociais (Poder Público, usuários de água e sociedade civil) na tomada de decisão e uma gestão de forma descentralizada (BRASIL, 1997; CAVALCANTI et al., 2016).

Tais dispositivos trazem um novo cenário na visão de águas no Brasil, uma vez que essa não mais é tida como um bem particular, mas público, atribuindo uma valoração econômica e ética no seu trato, principalmente quando prioriza o uso e neste caso, prioriza a vida e a afirmação democrática na abertura de espaço para a sociedade na tomada de decisões (JACOBI et al., 2007).

No que tange aos objetivos, no artigo $2^{\circ}$, incisos de I a IV da Política em comento, traz-se a necessidade de assegurar para as gerações atuais e futuras a disponibilidade de água em padrões de qualidade e quantidade, bem como o uso racional e integrado dos recursos hídricos, com o fim de promover o desenvolvimento sustentável, além disso, busca-se a prevenção e proteção contra eventos hidrológicos naturais ou em decorrência da ação humana, bem como promover o aproveitamento e captação de águas pluviais em vista a preservação do recurso (BRASIL, 1997). 
Acerca disto, Cavalcanti et al. (2016) observa que este modelo de política de gestão já adotado em muitos países, e agora pelo Brasil, conseguiu incorporar conceitos ratificados e recomendados por organismos internacionais como a ONU e a Agenda 21, quanto à promoção do desenvolvimento sustentável e a garantia de recurso para as atuais e futuras gerações.

Quanto aos instrumentos trazidos pela Lei 9.433/97 são apresentados como instrumentos de gestão da política o enquadramento dos corpos de água em classes de acordo com seus usos, planos de bacias, planos estaduais e Nacional de recursos hídricos, outorga do direito de uso, a cobrança pelo uso da água bruta e o sistema nacional de informações sobre recursos hídricos, ficando a cargo do artigo 5 o e seus incisos a sua enumeração que por ocasião serão disciplinados nas seções de I a VI que seguirão do artigo 6 ao 27은 como exposto no corpo da lei (BRASIL, 1997). Por sua vez, a implementação desses instrumentos é de caráter executivo; para isto a Lei 9.984 de 17 de julho de 2000 criou a Agência Nacional de Águas (ANA), órgão de gestão dos recursos hídricos de domínio da União para a execução e implementação destes (MACHADO, 2003; BRASIL, 2000).

Contudo, dois desses instrumentos tem sido bastante debatido na literatura e merecem mais atenção que é a cobrança pelo uso da água e a outorga para o direito de uso. No que diz respeito à cobrança pelo uso da água como instrumento da política, Graziera (2000) nos diz que esse não deixa de ser uma forma de controle ao atribuir a água um valor econômico com o intuito de que esta seja utilizada de forma racional e acrescenta que essa cobrança possui três finalidades básicas: a primeira que é a de reconhecer o valor econômico da água, a segunda, o despertar para o uso racional e por fim como instrumento financeiro da gestão, financiar os programas que estiverem contidos na política (GRAZIERA, 2000).

Entretanto, existem aqueles que são contrários a cobrança pelo uso da água, afirmando ser apenas mais um imposto. No entanto, o imposto como forma de tributo, previsto na Constituição de 1988 , não pode ter uma destinação pré-definida, o que é totalmente o contrário do que dispõe a lei de águas, conforme dispõe a lei 9.433/97. Os valores arrecadados da cobrança devem ser aplicados na bacia hidrográfica onde foram gerados de forma prioritária, e demais planos e projetos previstos nos planos de recursos hídricos (ZAGO, 2007).

Apesar de durante muito tempo a Associação Brasileira de Recursos Hídricos ( $A B R H)$ ter considerado que a cobrança pelo uso da água seria a solução para a crise hidrológica durante seus eventos, recentemente, sua visão tem sido mais crítica, no sentido de que esse é apenas mais um instrumento de colaboração com os objetivos e fundamentos da Política Nacional de Recursos Hídricos, e que por si só não é suficiente para resolver os problemas da água (CAMPOS et al., 2015; RODRIGUES et al., 2014).

Por sua vez, a outorga dos direitos de uso tem sido um dos instrumentos mais importantes para a viabilização dos objetivos e fundamentos da política Nacional de Recursos Hídricos e deve ser colocada em prática pelos os órgãos do sistema nacional de gerenciamento de recursos hídricos, tendo sido o único previsto constitucionalmente (FARIAS, 2008).

A instrução Normativa no 4/2000 do Ministério do Meio Ambiente conceitua a outorga do direito de uso como ato administrativo de autorização, onde o poder público outorgante concede ao outorgado o 
direito de uso por prazo determinado, completando esse entendimento Graziera (2001) define a outorga como um instrumento por meio do qual o Poder Público autoriza ao interessado público ou privado o direito de utilizar a água privativamente.

Assim, o objetivo da outorga, de acordo como o que dispõe o artigo 11 da Lei 9.433/97, é o de assegurar o controle qualitativo e quantitativo dos usos e acesso a água (BRASIL, 1997). Isso implica que não se deve haver nenhum privilégio para qualquer segmento, mas que esse acesso seja proporcionado de forma equitativa cumprindo os objetivos da Política em comento. Assim, a outorga deverá sempre preceder a cobrança, sendo dois instrumentos que devem ser tratados de forma conjunta (RODRIGUES et al., 2013).

Quanto à organização da Política Nacional de Recursos Hídricos, esta dispõe que o Conselho Nacional e os Conselhos Estaduais de Recursos hídricos serão responsáveis pela supervisão, normatização e regulação do sistema nacional e estadual de Gerenciamento de Recursos Hídricos. No que tange a secretaria de Recursos hídricos está tem a incumbência pela formulação da Política Nacional de Recursos Hídricos (PNRH), a ANA possui a responsabilidade pela implementação da política.

Já os comitês de bacias são órgãos políticos de tomada de decisão, quanto a utilização, proteção e recuperação das águas com a participação dos segmentos da sociedade, poder público, usuários de água e sociedade civil, por fim as agências de bacias que são instituições executivas dos comitês de bacas hidrográficos (BRASIL, 1997).

Outro ponto de destaque na política foi colocar a bacia hidrográfica como unidade de planejamento, tirando da esfera exclusivamente governamental o processo decisório e incorporando atores que eram excluídos da tomada de decisão que são os municípios, os usuários de água e a sociedade civil, transformando a bacia hidrográfica em um espaço democrático de debate em torno da tomada de decisões concernentes ao uso da água em nível de bacia.

A esse espaço de discussão no âmbito da Bacia hidrográfica enquanto unidade de planejamento reafirma o princípio da descentralização incorporado na PNRH, que é fortalecido e ampliado pelas as agências de bacia que tem a função do exercício de suporte técnico, financeiro e administrativo, bem como pela implementação dos instrumentos previstos na lei (CAVALCANTI et al., 2016). Vale salientar que a descentralização da gestão de recurso hídricos previsto na lei não modifica a titularidade do domínio das águas previsto na constituição que continuam sendo da União e dos Estados-membro (MENESES et al., 2014).

A partir dessa descentralização, surge outro ponto importante e inovador da PNRH, que é a gestão participativa que conta com três seguimentos, o poder público. Os usuários de água e a sociedade civil no processo decisório no âmbito da bacia hidrográfica, demostrando o acolhimento do princípio constitucional da democracia participativa (MENESES et al., 2014).

Essa gestão está inserida no tripé descentralização, participação e integração e esse sistema abre espaço para uma política participativa através de um processo decisório aberto aos segmentos sociais vinculados ao uso da água (JACOBI et al., 2007). Trata-se, portanto, de instâncias democráticas e colegiados decisórios onde serão discutidos a aprovação dos planos de gestão plurianuais das bacias e definição e aprovação de valores para a cobrança do uso da água (MAGALHÃES JUNIOR et al., 2003). Mais que isso, a 
gestão participativa assume cada vez mais um papel importante na denúncia de interesses públicos e privados e na condução de uma cidadania ambiental com bases e valores pautados na sustentabilidade (JACOBI, 2003).

Por fim, no que diz respeito ao Sistema Nacional de Gerenciamento de Recursos Hídricos - SNGRH criado pela política de água em cumprimento a regulamentação constitucional prevista no artigo 21 , inciso $\mathrm{XIX}$, este possui a incumbência para implementar a própria política, coordenar a gestão, preservar e recuperar os recursos hídricos, planejar e regular seu uso conforme artigo 32 da lei 9.433/97.

Fazem parte do SNGRH a Agência Nacional de Águas (ANA), o Conselho Nacional de Recursos Hídricos (CNRH), os conselhos dos Estado e do Distrito Federal, os comitês de bacias hidrográficas e os órgãos dos poderes Federal, Estadual e Municipal que tenham competência para tratar de recursos hídricos (RABELO, 2012; BRASIL, 1997).

Como visto, a PNRH possui mecanismos suficientes para uma boa gestão dos recursos hídricos. No entanto, ainda existem entraves para uma melhor efetivação, como acesso à informação por parte de todos os interessados, consciência ambiental para o uso racional, introdução no meio social da necessidade de reaproveitamento da água e principalmente a certeza de que este recurso é finito e, portanto, precisa ser preservado. No mais, o advento desta lei trouxe condições básicas para uma nova fase na gestão de recursos hídricos no Brasil, onde todos os usuários, as comunidades, todas as esferas governamentais podem decidir pelo melhor uso da água e investimentos necessários em torno de suas bacias (BOSOI et al., 1997).

\section{CONCLUSÕES}

A legislação brasileira apresentou uma evolução lenta, pois cada normatização foi influenciada por características e necessidades da época, sendo assim, observou-se que as primeiras normas a tratarem sobre águas, limitava-se a questões pontuais, restritas a competência dos entes federados. O Código de Águas de 1934, considerado o primeiro instrumento normativo específico para disciplinamento dos recursos hídricos no Brasil, foi na realidade um mecanismo de atendimento a interesses econômicos voltado para a construção de hidrelétricas na época.

Assim, a evolução maior pode ser observada a partir da Constituição Federal de 1988, que deu atenção especial ao meio ambiente em um capítulo próprio e em outros dispositivos espalhados ao longo da carta, colocando esse direito como clausula pétrea. A culminância do direito de águas no Brasil se deu com a publicação da Lei 9.433/97, a Política Nacional de Recursos Hídricos que regulamentou o inciso XIX do artigo 21 da Constituição Federal, pela instituição de um sistema de gerenciamento de recursos hídricos, representando um novo marco institucional no país, incorporando normas, princípios e padrões de gestão.

\section{REFERÊNCIAS}

ANA. Agência Nacional de Águas. Conjuntura dos recursos hídricos no Brasil 2017: relatório pleno. Brasília: ANA, 2017.

ARAÚJO, A. R.; BARBOSA, E. M.. Evolução do direito de águas no Brasil: uma visão histórico-jurídica. In: COLÓQUIO
INTERNACIONAL DE HISTÓRIA: SOCIEDADE, NATUREZA E CULTURA. Anais. Campina Grande: UFCG, 2008.

BARBOSA, E. M.; DANTAS NETO, J.. Direito das águas. Campina Grande: UFCG, 2004. 
BARBOSA, E. M.; BARBOSA, M. F. N.. Direito de Águas: Arranjo jurídico-institucional, política e gestão. Revista de Informação Legislativa, Brasília, n.49, 2012.

BITTENCOURT, V.; PEREIRA, D. E. S.. A evolução legislativa brasileira frente a problemática da água. Revista Brasileira de Direito, v.10, n.1, p.95-105, 2014.

BOSOI, Z. M. F.; TORRES, S. D. A.. A política de recurso hídricos no Brasil. Revista do BNDS, Rio de Janeiro, v.4, n.8, p.143-166, 1997.

BRASIL. Constituição da República dos Estados Unidos do Brasil. Brasília: DOU, 1981.

BRASIL. Constituição da República dos Estados Unidos do Brasil. Rio de Janeiro: 1934.

BRASIL. Constituição da República dos Estados Unidos do Brasil. Rio de Janeiro: 1937.

BRASIL. Constituição da República Federativa do Brasil de 1988. Brasília: DOU, 1988.

BRASIL. Decreto n.94076 de 5 de março de 1987. Institui o Programa Nacional de Microbacias Hidrográficas, e dá outras providencias. Brasília: DOU, 1987.

BRASIL. Lei n.9433 de janeiro de 1997. Institui a Política Nacional de Recursos Hídricos, cria o Sistema Nacional de Gerenciamento de Recursos Hídricos, regulamenta o inciso XIX do art. 21 da Constituição Federal, e altera o art. 1ㅇ da Lei $n$ o 8.001, de 13 de março de 1990, que modificou a Lei no 7.990, de 28 de dezembro de 1989. Brasília: DOU, 1997.

BRASIL. Lei $\mathbf{n} .9966$ de 28 de abril de 2000. Dispõe sobre a prevenção, o controle e a fiscalização da poluição causada por lançamento de óleo e outras substâncias nocivas ou perigosas em águas sob jurisdição nacional e dá outras providências. Brasília: DOU, 2000.

BRASIL. Lei $\mathbf{n . 9 9 8 4}$ de 17 de julho de 2000. Dispõe sobre a criação da Agência Nacional de Águas - ANA, entidade federal de implementação da Política Nacional de Recursos Hídricos e de coordenação do Sistema Nacional de Gerenciamento de Recursos Hídricos, e dá outras providências. Brasília: DOU, 2000.

BRASIL. Ministério do Meio Ambiente. Resolução CONAMA n.20 de 18 de julho de 1986. Brasília: MMA, 1986.

BRASIL. Ministério do Meio Ambiente. Resolução n.357 de 17 de março de 2005. Dispõe sobre a classificação dos corpos de água e diretrizes ambientais para o seu enquadramento, bem como estabelece as condições e padrões de lançamento de efluentes, e dá outras providências. Brasília: MMA, 2005.

BURITI, C. O.; BARBOSA, E. M.. Políticas Públicas de Recursos Hídricos no Brasil: olhares sob uma perspectiva jurídica e histórico-ambiental. Veredas do Direito, Belo Horizonte, v.11, n.22, p.225-254, 2014

CAMPOS, J. N. B.; CAMPOS, V. R.. A formação dos conhecimentos em recursos hídricos e aplicações em tomadas de decisões. Estudos Avançados, v.29, n.84, p.179194, 2015.

CASTRO, L. C.. A gestão dos recursos hídricos na bacia hidrográfica do alto Iguaçu-PR. Dissertação (Mestrado em Geografia) - Universidade Federal do Paraná, Curitiba, 2005.

CAVALCANTI, B. S.; MARQUES, G. R. G.. Recursos hídricos e gestão de conflitos na bacia hidrográfica do Rio Paraíba do Sul a partir da crise hídrica de 2014-2015. Revista de Gestão dos Países de Língua Portuguesa, Lisboa, v.15, n.1, 2016.

FARIAS, T. Q.. Outorga de direito de uso dos recursos hídricos no ordenamento jurídico brasileiro. Revista da ESMARN, Mossoró, v.8, n.1, p.469-484, 2008.

GRANZIERA, M. L. M.. Direito das águas: disciplina jurídica das águas doces. São Paulo: Atlas, 2001.

GRAZIERA, M. L. M.. A cobrança pelo uso da água. CEJ, Brasília, n.12, p.71-74, 2000.

HEIDMANN, F. G.. Do sonho do progresso às políticas de desenvolvimento. In: HEIDMENN, F. G.; SALM, J. F.. Políticas públicas e desenvolvimento. Brasília: UnB, 2006. p.23-39.

JACOBI, P. R.. Espaços públicos e práticas participativas na gestão do meio ambiente no Brasil. Sociedade e Estado, Brasília, v.18, n.2, p.315-338, 2003.

JACOBI, P. R.; BARBI, F.. Democracia e participação na gestão dos recursos hídricos no Brasil. Katálysis, Florianópolis, v.10, n.2, p.237-244, 2007.

MACHADO, C. J. S.. Recursos hídricos e cidadania no Brasil: Limites, alternativa e desafios. Ambiente \& Sociedade, v.6, n.2, 2003.

MAGALHÃES JUNIOR, A. P.; CORDEIRO NETTO, O. M. Ciência, cognição e informação na operacionalização da gestão participativa da água no Brasil. Sociedade e Estado, Brasília, v.18, n.2, p.221-256, 2003.

MENESES, R. M.; BIESEK, C. B.. Gestão participativa de comitê: um estudo sobre a participação dos segmentos (usuários da água, Poder Público e sociedade civil) no Comitê da Bacia Hidrográfica do Rio do Peixe. Direito Ambiental e sociedade, v.4, n.2, p.229-256, 2014.

RABELO, D. C.. Informação e comunicação na gestão participativa: uma análise a partir das políticas de recursos hídricos do Brasil e da Europa. Emancipação, Ponta Grossa, v.12, n.2, p.253-264, 2012.

RODRIGUES, M. V. S.; AQUINO, M. D.. Análise comparativa entre a cobrança pelo uso da água bruta do estado do Ceará com a cobrança aplicada no estado de São Paulo. REGA, v.11, n.2, p.37-51, 2014

RODRIGUES, M. V. S.; AQUINO, M. D.. Estrutura legal da gestão das águas no Estado do Rio Grande Norte. Revista de Gestão de Águas da América Latina, v.10, n.1, p.17-28, 2013.

SANTIN, J. R.; GOELLNER, E.. A Gestão dos Recursos Hídricos e a Cobrança pelo seu Uso. Sequência, Florianópolis, n.67, p.199-221, 2013 
ZAGO, V. C. P.. A valoração econômica da água - uma reflexão sobre a legislação de gestão dos recursos hídricos do Mato Grosso do Sul. Revista Internacional de

Desenvolvimento Local, v.8, n.1, p.27-32, 2007.

A CBPC - Companhia Brasileira de Produção Científica (CNPJ: 11.221.422/0001-03) detém os direitos materiais desta publicação. Os direitos referem-se à publicação do trabalho em qualquer parte do mundo, incluindo os direitos às renovações, expansões e disseminações da contribuição, bem como outros direitos subsidiários. Todos os trabalhos publicados eletronicamente poderão posteriormente ser publicados em coletâneas impressas sob coordenação da Sustenere Publishing, da Companhia Brasileira de Produção Científica e seus parceiros autorizados. Os (as) autores (as) preservam os direitos autorais, mas não têm permissão para a publicação da contribuição em outro meio, impresso ou digital, em português ou em tradução. 